\title{
IMPLEMENTATION OF THE Digital TWIN METHODOLOGY
}

\author{
Petr Janda, Zdenek Hajicek \& Petr Bernardin
}
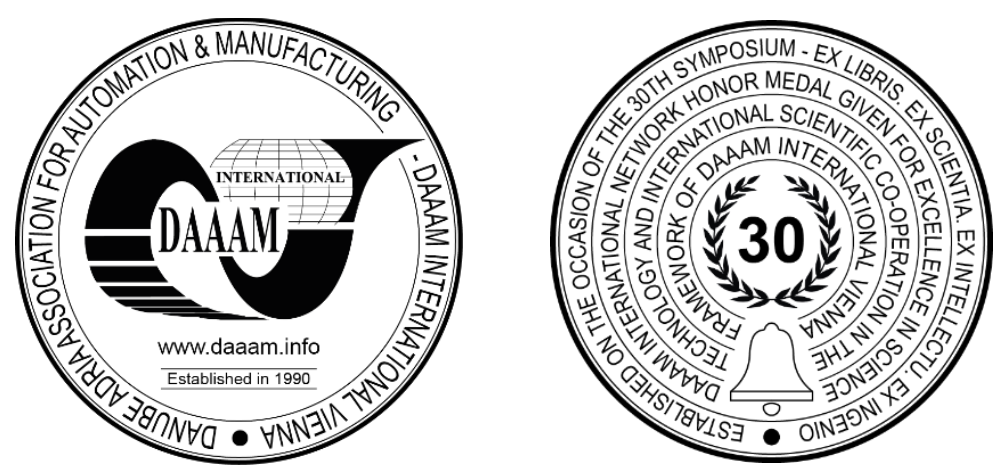

This Publication has to be referred as: Janda, P[etr]; Hajicek, Z[denek] \& Bernardin, P[etr] (2019). Implementation of The Digital Twin Methodology, Proceedings of the 30th DAAAM International Symposium, pp.0533-0538, B. Katalinic (Ed.), Published by DAAAM International, ISBN 978-3-902734-22-8, ISSN 1726-9679, Vienna, Austria DOI: $10.2507 / 30$ th.daaam.proceedings.072

\begin{abstract}
According to Industry 4.0 the process of digitization in manufacturing companies has advanced to the virtualization phase. The final state should be a complete virtualization of the production plant. However, virtualization has a high demand for innovation. This article summarizes the findings of the implementation of the "Digital Twin" methodology in a real manufacturing company. The main topic is virtualization of heavy machine tools of Skoda Machine Tool Co. For the virtualization are used modern software tools Siemens NX, Mechatronic Concept Designer, Simit and VNCK kernel.
\end{abstract}

Keywords: mechatronic concept; virtual commissioning; digital twin; heavy machine tool

\section{Introduction}

Digital Twin is one of the areas of The Industry 4.0. This topic is very popular and there are many articles dealing with it [1], [2]. The basic idea is to take digitization to the level of complete virtualization. Many manufacturing companies have already reached a very high level in the digitization process and therefore logically look for further innovation opportunities. Leaders in this area are traditionally aerospace and automotive companies. But traditional heavy machine tool manufacturers respond much more slowly to innovation. Thanks to the very good cooperation of the University of West Bohemia and the manufacturer of heavy machinery Skoda Machine Tool we have the opportunity to change this.

The history of machine tool production in Pilsen dates back to 1911. At present, Škoda Machine tool produces one of the largest machine tools in the world. In cooperation with the University of West Bohemia, virtualization tools are significantly integrated into the product life cycle. Thanks to computational and optimization software tools we are able not only to improve current machines but also to design new machines. Achieving further improvement through the implementation of the digital twin methodology is a major challenge.

The process of implementation of this methodology began as early as 2015 when the first virtual machine on the Sinumerik VNCK kernel was created. In the following years, a virtual machine based on the Mechatronic Concept Designer (MCD) was implemented in combination with real control using the Sinumerik 840D system. There are currently two ways to create a digital twin, VNCK and MCD. The ability to implement digital twin methods has also been presented at international engineering fairs in Stuttgart and Hanover. This article summarizes the findings from the implementation of the digital twin methodology and describes the advantages and disadvantages of each method. 


\section{Literature overview}

The relevance of the topic is demonstrated by studies on Industry 4.0 [1], [2], [3]. Especially in 2015 there was a significant increase in the number of articles dealing with this topic. Ovtcharova [4] describes in her article the exhaustion of possibilities for improvement through digitization and the advent of new innovations through virtualization.

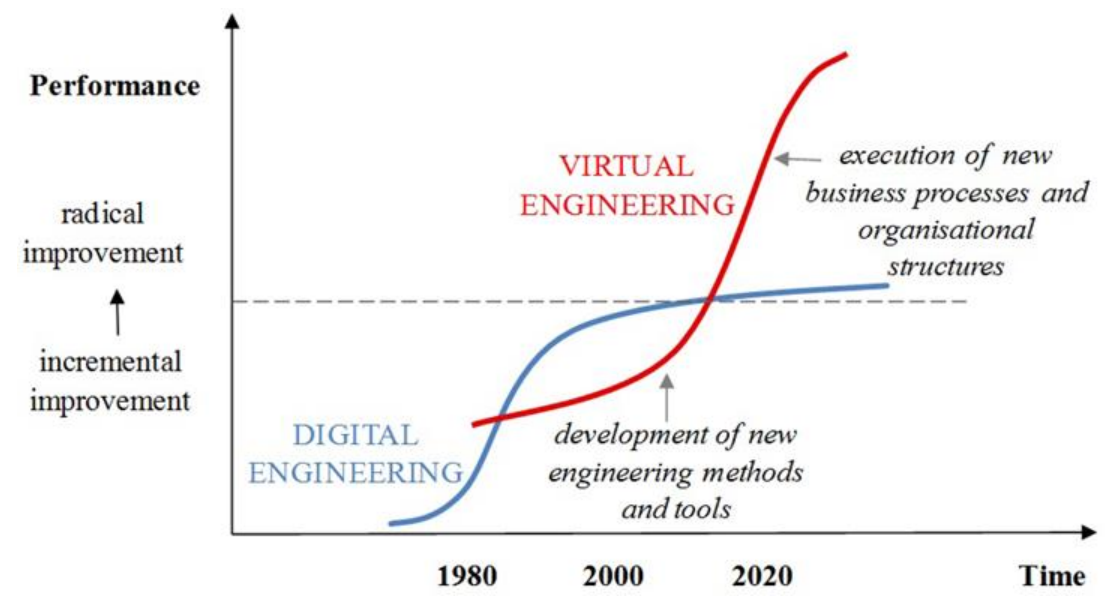

Fig.1. Transformation of digitization into virtualization [4]

The implementation of the digital twin methodology is very important for the future of manufacturing [5]. There are many articles on this topic describing the creation of a mechatronic model [6], [7], [8], [9]. Most authors apply this methodology primarily to small machines. The topic of using a digital twin in heavy machine tools is quite unique.

\section{Virtual model of Digital Twin}

There are two ways to create a digital twin. The first is the possibility of using the VNCK core, which allows you to run a virtual machine fully software. The second option is realization by connecting the virtual model to real hardware. This variant is primarily based on the Siemens Mechatronics Concept Designer.

\section{1. $V N C K$}

The meaning of shortcut VNCK is Virtual Numerical Controller Kernel. Virtual twin is based on virtual copy of machine controller Sinumerik 840 D Solution Line. This kernel consist of the same interpolator system and all NC processes are driven like by real controller. By this virtual controller are possible make tests of real standard machine cycles or prepare special user defined cycles in the virtual phase. The main setup of the kernel is based on real machine archive file. This machine archive consists of all machine variables with setup of kinematic structure, motor settings, subprograms of cycles and other. [10]

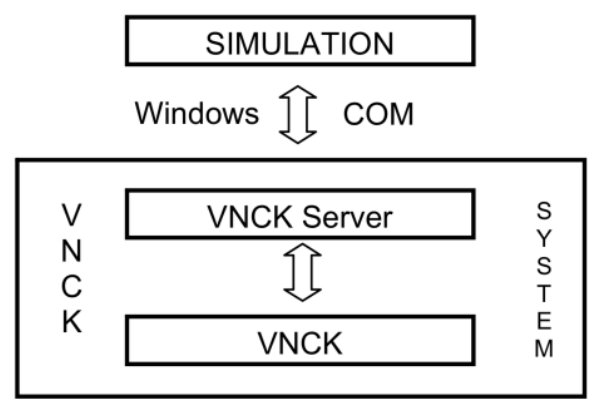

Fig. 2. Architecture of VNCK twin [11]

The picture Fig. 2. shows the principle of VNCK architecture. VNCK system consists of many software components. The main components are VNCK kernel and VNCK Server which guarantee communication between VNCK system and simulation software. Simulation software v 3D machine kinematic model in simulation interface Siemens NX ISV module. 
ISV (Integrated Simulation and Verification) is additional module of CAD/CAM system NX. VNCK Server can send signals about machine motions by Windows COM interface. This process is important because simulation software must sent back to the VNCK Server information about real simulated machine positons. [11]

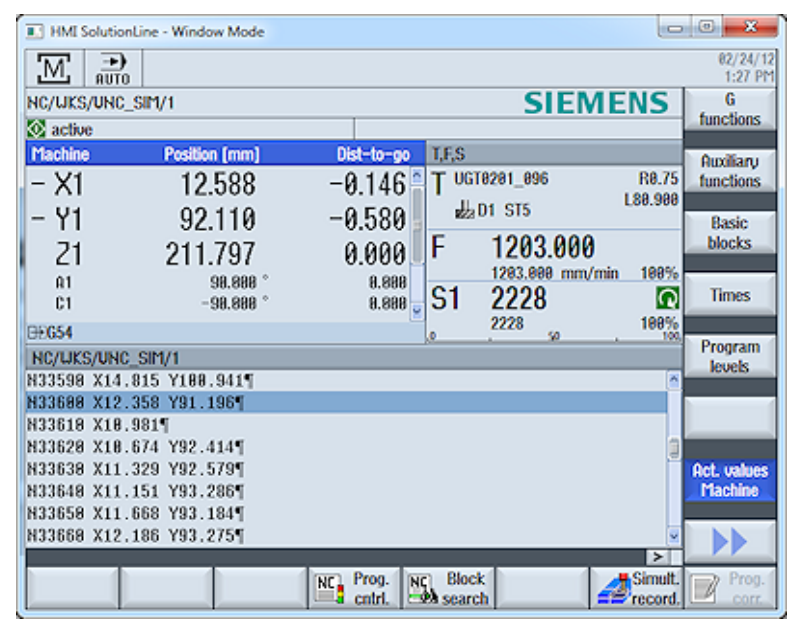

a)

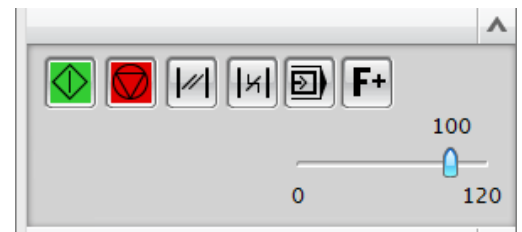

b)

Fig. 3. HMI interface and ISV simulation controller panel [11]

On the picture Fig. 3a is showed HMI (Human Machine Interface) interface of virtual machine controller panel Sinumerik Operate for PC. We can see actual axis position, used name of cutting tool, feed of tool, speed and real NC program. On the picture Fig. 3b is showed VNCK simulation controller panel in interface ISV module. Virtual controller interpret the NC program in signals form and this signals drive motions of virtual machine twin. This controller in the background drives other accessories like industry computer (IPC), sensors and PLC (Programmable Logic Controller), drivers of electric motors. [11]

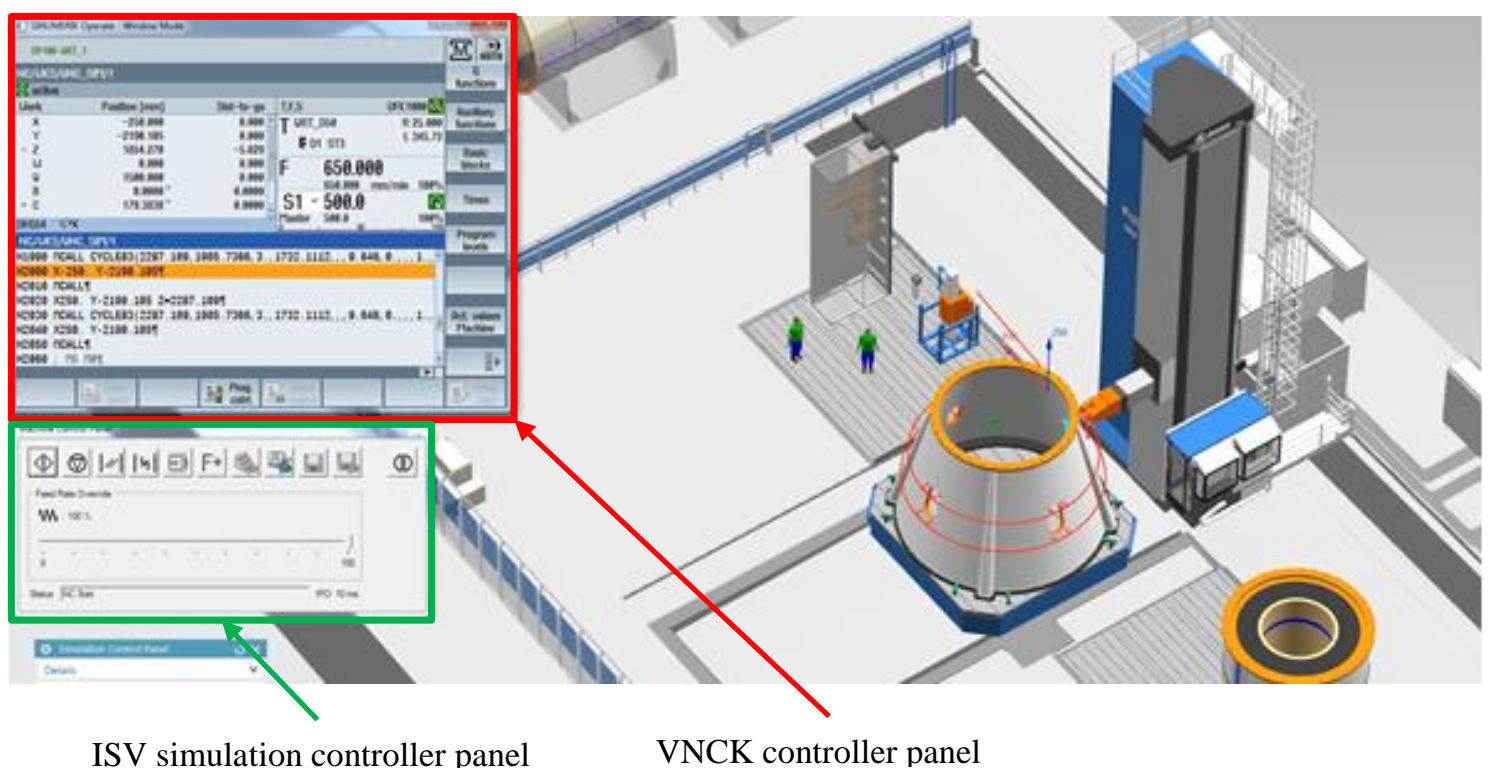

Fig. 4. Final virtual twin based on VNCK

The final virtual twin based on VNCK simulation kernel is showed on the picture Fig. 4. On the picture we can see 3D kinematic model of the horizontal boring machine, ISV simulation controller panel and VNCK controller panel. The ISV simulation controller panel is used for controlling of the machine tool simulation. The VNCK controller panel is used for setting of NC programs and driving the virtual machine like the reality. By this simulation the CAM programmer can make analysis of machining time, make collision analyse, check and optimise the NC program for the specific machine tool. 


\subsection{Digital Twin Development}

Using MCD, the digital twin is created as hardware in the loop solution. This solution consists of three basic parts: Virtual Model, Filedbus Emulator and Sinumerik 840D Control System. The composition of the real and virtual machines is shown in Figure 5.

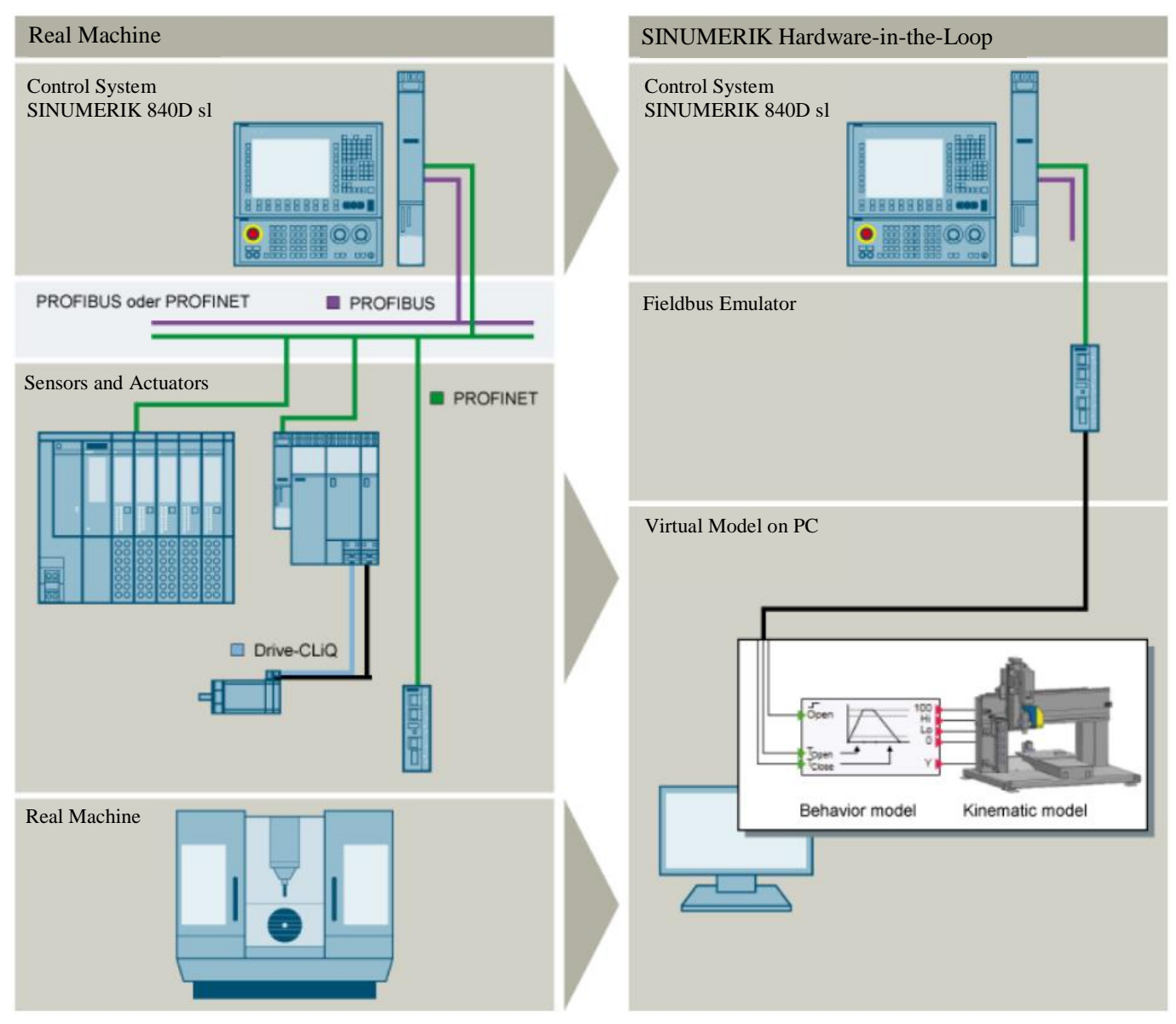

Fig. 5. Transformation of digitization into virtualization [12]

\section{Virtual model}

The virtual model runs completely on a PC and consists of a kinematics model and a behaviour model. Siemens NX Mechatronic Concept Designer and Simit software tools are used to create these models.

The kinematic model uses 3D models made by the designer, which are simplified for simulation purposes. Individual rigid bodies are defined and then connected by joints. This allows the virtual machine to perform the same movements as in reality.

Modelling of machine behaviour is realized in software Simit, which allows to simulate PLC program. The basic element for machine tools is the movement of controlled axes by means of the ADAS block, which ensures the transformation of the control signal into the position of individual actuators.

\section{Fieldbus Emulator}

A fieldbus emulator, also called a Simulation Unit, is used to emulate the communication behaviour between I/O devices. The actual control signals from the SINUMERIK are transferred from the Simulation Unit to a PLC.

\section{Sinumerik 840 D Control System}

The real hardware of Sinumerik $840 \mathrm{D}$ is used to control the virtual model. This hardware is the same as for real machine control. This makes it possible to test different system settings much sooner than a real machine is made. This setting can then be transferred to a real machine. 


\section{Results}

The results can be divided into two development branches: MCD and VNCK. It also includes a comparison of both methods.

\subsection{Development of the Digital Twin based on Mechatronic Concept Designer}

During the implementation of the digital twin into the manufacturing processes of the machine tool manufacturer, virtual commissioning of both main machine types were successfully. Based on the knowledge of the virtual commissioning of the horizontal boring machine [13], this year a project focused on the digital twin heavy lathe was realized. The virtual heavy lathe model is characterized by a large number of accessories that need to be changed during the machining process. The results of this development were presented at the EMO in Hannover 2019. Figure 6 shows the digital twin based on the MCD hardware in the loop methodology.

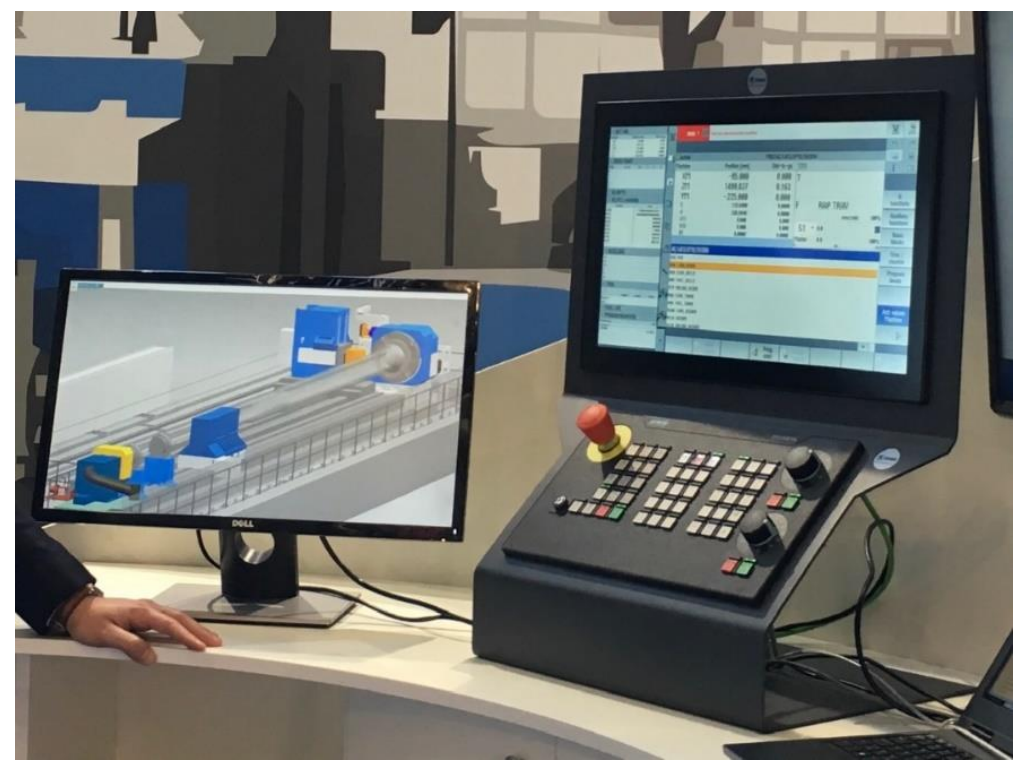

Fig. 6. Presentation of digital twin at EMO Hannover 2019

\subsection{Development of the Digital Twin based on VNCK kernel}

This theses describe the principles of modern virtual twin based on VNCK. By this project was tested possibilities of and main functionality of VNCK simulation focused on heavy machine tools. The subprogram of head changing with automatic changing of kinematic machine structure was developed. VNCK digital twin was implemented to the PLM system Teamcenter and simulation of NC program is provided by server platform. The NC program for special milling and turning application was tested and optimized by this simulation.

\subsection{Comparison of methodologies based on Mechatronic Concept Designer and based on VNCK kernel}

Each method of creating a digital twin has its advantages and disadvantages, which were found during the implementation of the solutions. A comparison of the two methods is given in Table 1.

\begin{tabular}{|l|l|l|}
\hline & \multicolumn{1}{|c|}{ Based on VNCK kernel } & Based on Mechatronic Concept Designer \\
\hline Main applications & $\begin{array}{l}\text { CNC program simulation. Determination } \\
\text { of machine time. }\end{array}$ & $\begin{array}{l}\text { Development of new machines. Testing of } \\
\text { machine tool behaviour. }\end{array}$ \\
\hline Advantages & $\begin{array}{l}\text { Simulation of material removal during } \\
\text { machining. }\end{array}$ & $\begin{array}{l}\text { Real hardware (Sinumerik 840D control } \\
\text { panel). }\end{array}$ \\
\hline Disadvantages & $\begin{array}{l}\text { It does not include machine dynamics } \\
\text { effects. }\end{array}$ & Body compliance is not included. \\
\hline
\end{tabular}

Table 1. Comparison of the Digital Twin Methods 


\section{Conclusion}

The methodology of digital twin creation and its implementation was successfully solved. Two methodologies for creating a digital twin have been integrated into the machine tool manufacturing processes. Increasingly, VNCK-based simulators have been created as part of the supply of machining centres to the customer. There are also requirements for using a virtual machine with a real control panel. The implementation of the digital twin methodology was presented for the second year at international engineering fairs in Stuttgart and Hanover.

In the case of MCD solutions, there is a great potential in improving the Digital Twin. By integrating other software tools, it is possible to bring the effects of hydraulics or heat into the model. This will be subject to further development. Another important task is to compare the results obtained from the virtual model with the real ones.

\section{Acknowledgments}

The paper was supported by project FV10219 - Multipurpose turning centre for machining large and complex parts of a rotating character designed for power engineering and renewable resources.

\section{References}

[1] Liao, Y., Deschamps, F., Loures, E. D. F. R., \& Ramos, L. F. P. (2017). Past, present and future of Industry 4.0-a systematic literature review and research agenda proposal. International journal of production research, 55(12), 3609-3629.

[2] Zhong, R. Y., Xu, X., Klotz, E., \& Newman, S. T. (2017). Intelligent manufacturing in the context of industry 4.0: a review. Engineering, 3(5), 616-630.

[3] Roblek, V., Meško, M., \& Krapež, A. (2016). A complex view of industry 4.0. Sage Open, 6(2), 2158244016653987.

[4] Ovtcharova, J. G. (2010) Virtual Engineering: Principles, Methods and Applications, International Design Conference - DESIGN 2010, Dubrovnik, 1267-1274

[5] Rosen, R., Von Wichert, G., Lo, G., \& Bettenhausen, K. D. (2015). About the importance of autonomy and digital twins for the future of manufacturing. IFAC-PapersOnLine, 48(3), 567-572.

[6] Luo, W., Hu, T., Zhang, C., \& Wei, Y. (2018). Digital twin for CNC machine tool: modeling and using strategy. Journal of Ambient Intelligence and Humanized Computing, 1-12.

[7] Konstantinov, S., Ahmad, M., Ananthanarayan, K., \& Harrison, R. (2017). The Cyber-Physical e-machine Manufacturing System: Virtual Engineering for Complete Lifecycle Support. Procedia CIRP, 63, 119-124.

[8] Mcharek, M., Azib, T., Hammadi, M., Choley, J. Y., \& Larouci, C. (2018). Knowledge sharing for mechatronic systems design and optimization. IFAC-PapersOnLine, 51(11), 1365-1370.

[9] Yang, W., Tan, Y., Yoshida, K., \& Takakuwa, S. (2017). Digital twin-driven simulation for a cyber-physical system in Industry 4.0. DAAAM International Scientific Book, 227-234.

[10] Hajicek, Z; Marek, V. (2017). Simulation of Virtual Machine Tool during the Machine Design, Proceedings of the 28th DAAAM International Symposium, Published by DAAAM International, ISBN 978-3-902734, ISSN 17269679, Vienna, Austria

[11] Siemens AG. (2017). Internal documentation of Siemens PLM Software

[12] First steps - instructions for virtual commissioning with SINUMERIK 840D sl, Siemens AG. (2017). Internal documentation of Siemens PLM Software

[13] JANDA, P. Mechatronic concept of heavy machine tools. In Annals of DAAAM and Proceedings of the International DAAAM Symposium Volume 29, Issue 1, 2018. Vienna: Danube Adria Association for Automation and Manufacturing, DAAAM, 2018. 645-652. ISBN: 978-3-902734-20-4 , ISSN: 1726-9679 